\title{
Spatial Distribution Law of Vibration Acceleration of Ultra-small-spacing Tunnel under Train Moving Loads
}

\author{
Shuren Wang ${ }^{1,2^{*}}$, Kunpeng Shi ${ }^{1}$, Zhenhua $\mathrm{Li}^{1}$, Zhichao $\mathrm{Li}^{1}$ and Yunfei Wang ${ }^{1}$ \\ ${ }^{1}$ International Joint Research Laboratory of Henan Province for Underground Space Development and Disaster Prevention, \\ Henan Polytechnic University, Jiaozuo 454003, China \\ ${ }^{2}$ School of Minerals and Energy Resources Engineering, University of New South Wales, Sydney, NSW 2052, Australia
}

Received 17 July 2019; Accepted 1 December 2019

\begin{abstract}
The operation safety of ultra-small-spacing subway tunnels is seriously threaten by long-term, high-frequency, low amplitude train vibration loading. Although the vibration loading generated by the train is small each time, the durability of the tunnel structure may be reduced or even cracked under long-term impact. To study the spatial distribution law of vibration acceleration of ultra-small-spacing tunnels under train moving loading, a three-dimension numerical model was established for a subway-track tunnel with a design speed of $120 \mathrm{~km} / \mathrm{h}$, and the spatial distribution law of vibration acceleration of the subway track system and surrounding rocks of the tunnel with single train running, double trains running in the same direction and double trains running in the reverse direction were analyzed. Results show that the vertical acceleration of the wheel-rail contact point is always the largest in the longitudinal direction, and the vertical acceleration of waist of the middle rock pillar wall is about $60 \%$ of the bottom of the roadbed. The vertical acceleration of the surrounding rock of the tunnel satisfies the distribution law of the exponential function in both the horizontal and vertical directions. The vertical acceleration propagates along the midline to both sides in the lateral direction, the vertical acceleration attenuates about $80 \%$ at $6 \mathrm{~m}$ and $95 \%$ at $10 \mathrm{~m}$. The vertical acceleration at the waist of the middle rock pillar wall is the largest in the vertical direction, and its attenuate sharply to both ends of the rock pillar. After $10 \mathrm{~m}$, the attenuation rate gradually becomes gentle. The obtained conclusions can provide the theoretical base in the design and construction of similar engineering.
\end{abstract}

Keywords: Subway tunnel, Ultra-small-spacing, Middle pillar, Vibration acceleration, Moving loading

\section{Introduction}

In recent years, with the rise of urban subway engineering, the problem of environmental vibration caused by subway operation becomes more and more prominent, and researchers pay more and more attention to it. The number of railway tunnels increasing sharply will inevitably lead to subway tunnels with small clear distances or ultra-small distances. Due to the unevenness of the track, and the eccentric scars of the wheels, the train vibration loads caused by the high-speed train moving will induce dynamic response in the tunnel structure [1-2].

During the train long-term operation, the tunnel structure will continue to suffer from the impact of the train vibration loading, which leads to the decrease of the durability of the tunnel structure and even the cracking. The long-term impact of the train vibration loading with low-amplitude and high frequency is one of the main factors that affect the safety of the subway tunnel structure.

Therefore, to provide a theoretical basis for the safety evaluation of tunnel structures under train vibration loads and the design of vibration reduction schemes, it is of great significance to study the dynamic response and attenuation law of ultra-small-spacing tunnel structures under high-

*E-mail address: w_sr88@163.com ISSN: 1791-2377 @ 2019 School of Science, IHU. All rights reserved. doi:10.25103/jestr.126.12 speed train moving loading.

\section{State of the Art}

With regard to the dynamic response of the surrounding structure caused by the train moving loading, some scholars have done a lot of work. For examples, taking Shanghai Metro as the engineering background, the tunnel dynamic responses were analyzed. $\mathrm{Li}$ et al. found that the point displacement and time-history curve of track bed was basically the same, but both the moving wheel load and the excitation force function would cause errors in the acceleration spectrum distribution [3]. Bian et al. studied the influence of track irregularity of four typical wavelengths on track vibration, they found that the vibration response on the long wave path had higher vibration frequency and higher vibration response [4]. Xue et al. conducted the threedimension simulation analysis to found the dynamic stress value of the tunnel lining and the inverted arch was small, but the effect of the dynamic stress rate of the inverted arch and the tunnel lining was much greater than that of foundation clay, and the vertical stress decreased along the depth of the soil [5-6].

The long-term dynamic loading of the train will cause the deformation of the tunnel structure and the overall sinking to increase year by year, but the sinking amplitude is small [7]. Zhou et al. combined the physical experiments and 
numerical simulations, they found that as the number of vibration loads increased, the growth rate of the cumulative deformation of the tunnel structure gradually decreased, and the cumulative deformation curve had a significant turning point [8]. Yuan et al. established the coupling model between the tunnel and the track system by using the analytical method, they found that the displacement response of the saturated soil was significantly different from the elastic soil, and the type of soil had less influence on the response of the track structure [9].

Zhou et al. proposed a finite element-boundary element method to analyze the dynamic response of a shield tunnel in a saturated soil. They found that the influence of the tunnel joints on the ground vibration level was largely dependent on the frequency of dynamical load. The long-term train load had a significant impact on the dynamic characteristics of the soil, and it is necessary to consider the segment joints when studying the impact of the long-term train load on the tunnel [10-11]. The additional internal force of shield tunnel with segment lining (joint interface) was larger than that of shield tunnel with homogeneous equivalent stiffness model, In addition, the secondary lining could significantly inhibit the development of segmental lining cracking and reduced the internal force of bolts [12-13]. Yi et al. studied the cumulative deformation mechanism of tunnel lining under long-term dynamic load, and they found that the deformation of lining ring increased slightly at the beginning and significantly later due to joint dislocation and opening [14]. Seong et al. studied the dynamic response of rigid lining with different curvature under the train wind load, they found that the higher the vehicle speed, the greater the dynamic response, and the smaller the dynamic response when the curvature was greater [15].

Since the impact of long-term dynamic loads on the surrounding rock of ultra-small-spacing tunnels during train running is unclear, and there is little reported in this field. Taking Guangzhou Metro Line 3 as an example to study the section from Gangding to Shipaiqiao, the three-dimension model for the interaction of subway vehicles, tracks, track beds, and foundations was established, the spatial distribution characteristics of vibration acceleration of ultrasmall-spacing tunnels under long-term dynamic loads was analyzed by using numerical simulation analysis, the spatial distribution law of vibration acceleration of ultra-smallspacing tunnel track system, middle rock pillar, and surrounding rock was revealed.

The rest of this study is organized as follows. Section 3 describes the relevant background and the numerical analysis method. Section 4 gives the results and discussion, and finally, the conclusions are summarized in Section 5.

\section{Methodology}

\subsection{Engineering background}

Taking the section of Gangpai-Shipaiqiao of Guangzhou Metro Line 3 as an engineering case, Guangzhou Metro Line 3 with a double-line tunnel with a clear distance of about $200 \mathrm{~mm}$ is buried at a depth of $15 \mathrm{~m}$ from the tunnel arch top The tunnel in this section crosses Tianhe Road above the underground, the ground traffic is busy, and both sides of this road are high-rise and multi-storey buildings. The buried depth of the tunnel track surface is $16-19 \mathrm{~m}$, the inner diameter of the tunnel is $5.2 \mathrm{~m}$, the outer diameter is $6 \mathrm{~m}$, and the lining is $0.4 \mathrm{~m}$, C50 precast concrete is used, as shown in Fig. 1 [16].

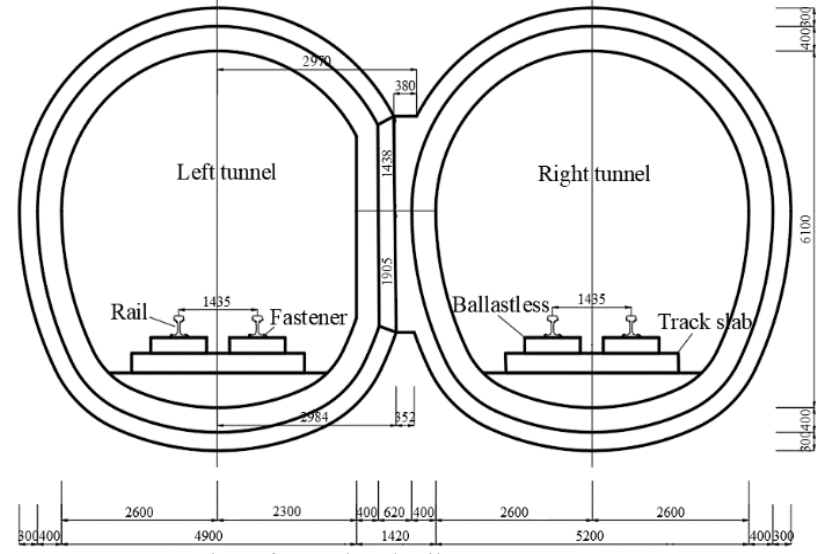

Fig. 1. Cross-section of tunnel and rail system.

According to the geological survey report, the type of landform passing through this section of Line 3 is mainly the Zhujiang river stacking terrace. The tunnel floor is basically located in strongly weathered, medium weathered and slightly weathered rock formations. The overlying strata of the tunnel is mainly strongly weathered, residual layer, silty clay and sand layer. The geological section of the tunnel is shown in Fig. 2 [17].

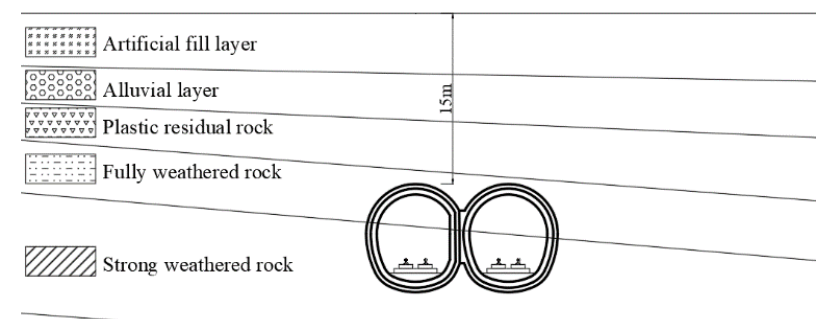

Medium weathered rock

Fig. 2. Geological section of the tunnel.

\subsection{Computational model and its parameters}

\subsubsection{Building computational model}

To study the dynamic response of the ultra-small-spacing tunnel during the running of high-speed trains, the threedimension computational model was established by using the software ABAQUS.

The model was divided into two parts: the finite element and the infinite element models. The infinite element was used to approximately simulate the infinite ground foundation, so as to eliminate the elastic recovery of the outer model of the boundary and the reflection of waves. The finite element model was $90 \mathrm{~m}$ long, $60 \mathrm{~m}$ wide, and 40 $\mathrm{m}$ high. The size of the infinite element model was ten times that of the finite element model [14]. As shown in Fig. 3, the dimensions of the tunnel and track system were consistent with the actual dimensions shown in Fig. 1.

In the model, the C3D8R reduced integral grid element type was used to simulate soil, lining and track system. Infinite element model adopted the CIN3D8 infinite element grid type. Since the force of the rail contact spot is extremely complicated and non-uniformly distributed, when the pressure of the contact spot exceeds $1000 \mathrm{MPa}$, the convergence of the calculation analysis is a huge challenge. To meet the needs of dynamic analysis stability, the grid must be fine enough, which will inevitably increase the 
model calculation time [18]. Due to the direct contact between the track system and the moving load of the train, the grid division of the track system is relatively fine. The grid size of the rails is $0.05 \mathrm{~m}$, and the grid size of the sleepers and track slabs is $0.10 \mathrm{~m}$. The number of elements in the whole model is 334838 , the number of nodes is 514646 , and the number of degrees of freedom is 1533186 . The analysis process in this study includes four stages: the generation of the initial stress field of the original field, the tunnel excavation and support, the construction process of the track system, and the application of moving loads.

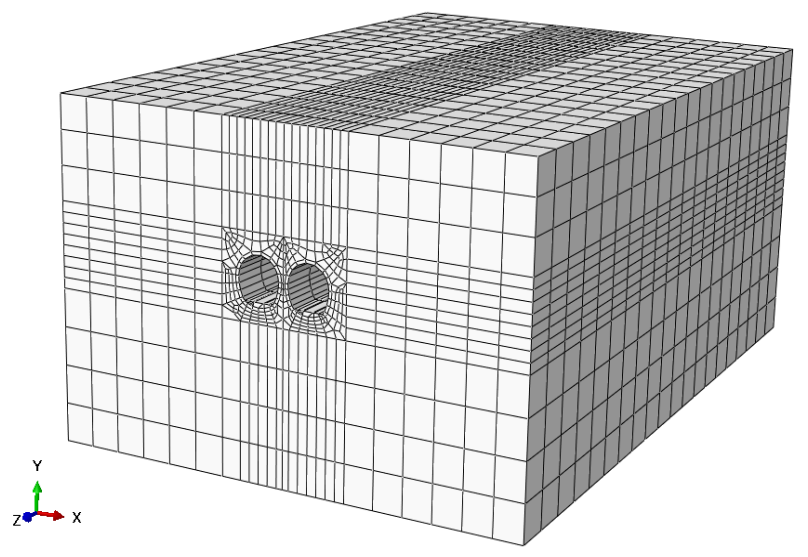

(a) Finite element model

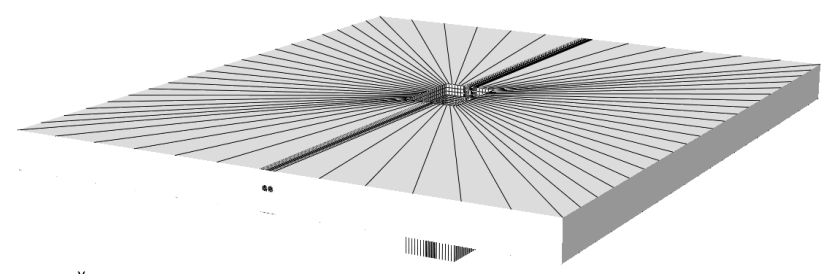

$\underset{z}{\stackrel{r}{\longrightarrow} \times x}$

(b) Infinite element model

Fig. 3. The computational model and its meshes.

\subsubsection{Calculation parameters}

The geological survey results were generalized appropriately, and the site strata was roughly divided into six layers from top to bottom: artificial fill, alluvial layer, plastic residual rock, fully weathered rock, strongly weathered rock and moderately weathered rock. The tunnel was mainly located in the strongly weathered, moderately weathered and slightly weathered rock. The physical and mechanical parameters obtained from laboratory tests are shown in Table 1. Mohrcoulomb constitutive was adopted for the surrounding rock of the tunnel. According to the relevant provisions of the industry standard high-speed railway design specification of China (TB 10621-2009), the linear elastic constitutive was adopted for the lining, track, fastener system, sleeper, track slab and other track systems of the tunnel. The main relevant parameters are shown in Table 2.

Table 1. Calculating parameters for the model.

\begin{tabular}{|c|c|c|c|c|c|c|c|}
\hline \multirow[b]{2}{*}{ Name } & \multirow{2}{*}{$\begin{array}{c}\text { Weight } \\
\left(\mathrm{kN} / \mathrm{m}^{3}\right)\end{array}$} & \multirow{2}{*}{$\begin{array}{l}\text { Elastic modulus } \\
(\mathrm{GPa})\end{array}$} & \multirow{2}{*}{$\begin{array}{l}\text { Poission's } \\
\text { Ratio }\end{array}$} & \multirow{2}{*}{$\begin{array}{c}\text { Cohesion } \\
\text { (MPa) }\end{array}$} & \multirow{2}{*}{$\begin{array}{c}\text { Friction angle } \\
\left({ }^{\circ}\right)\end{array}$} & \multicolumn{2}{|c|}{ Ravleigh damping } \\
\hline & & & & & & $\alpha\left(\mathbf{s}^{-1}\right)$ & $\beta(\mathrm{s})$ \\
\hline $\begin{array}{l}\text { Artificial fill layer } \\
\text { Alluvial layer }\end{array}$ & $\begin{array}{l}19.6 \\
19.2\end{array}$ & $\begin{array}{l}0.10 \\
0.12\end{array}$ & $\begin{array}{l}0.42 \\
0.33\end{array}$ & $\begin{array}{l}0.024 \\
0.014\end{array}$ & $\begin{array}{l}16 \\
22\end{array}$ & $\begin{array}{l}0.2620 \\
0.2295\end{array}$ & $\begin{array}{l}0.0244 \\
0.0214\end{array}$ \\
\hline Plastic residual rock & 19.4 & 0.18 & 0.33 & 0.023 & 25 & 0.2132 & 0.0206 \\
\hline Fully weathered rock & 19.9 & 0.41 & 0.28 & 0.033 & 29 & 0.2332 & 0.0224 \\
\hline Strong weathered rock & 21.4 & 0.65 & 0.35 & 0.088 & 33 & 0.2056 & 0.0198 \\
\hline Medium weathered rock & 24.0 & 1.10 & 0.32 & 0.130 & 36 & 0.2113 & 0.0203 \\
\hline
\end{tabular}

Table 2. Calculating parameters for the rail system.

\begin{tabular}{c|c|c|c|c|c}
\hline \multirow{2}{*}{ Name } & Weight & Elastic modulus & Poission's & \multicolumn{2}{c}{ Ravleigh damping } \\
\cline { 3 - 6 } & $\left(\mathrm{kN} / \mathrm{m}^{3}\right)$ & $(\mathbf{G P a})$ & Ratio & $\alpha\left(\mathbf{s}^{-\mathbf{1}}\right)$ & $\beta(\mathrm{s})$ \\
\hline Rail & 78.0 & 206 & 0.32 & 0.2620 & 0.0244 \\
Slacper & 24.0 & 30 & 0.13 & 0.2295 & 0.0214 \\
Track slab & 24.0 & 35 & 0.13 & 0.2132 & 0.0206 \\
\hline Funneling lining & 24.0 & 31 & 0.13 & 0.2332 & 0.0224 \\
\hline
\end{tabular}

\subsubsection{Boundary conditions}

When the finite element method is used to analyze the dynamic response of the soil on semi-infinite foundations, the fixed boundary conditions will cause the wave energy to be reflected back and forth in the calculation domain, which will amplify the effect of the wave. The artificial boundary can absorb the scattered wave energy and the reflection effect of waves. In addition, the artificial boundary calculation results are more reasonable than the fixed boundary when simulating the propagation of vibration waves to infinity in the ground [19].

ABAQUS provides two methods for setting artificial boundaries: viscoelastic artificial boundaries and infinite element artificial boundaries. ABAQUS infinite element artificial boundary is significantly better than viscoelastic artificial boundary in the filtering of waves. Moreover, when the infinite element artificial boundary is used to simulate waves propagation in infinite ground, the calculation time of the model can be greatly shortened without losing the calculation accuracy [20].

\subsubsection{Loading conditions}

The axle weights of subway trains are generally 9-10 tons under no loading conditions, and which is about 13-14 tons at full capacity. This study only considers the vertical loading of the train. Two trains were selected for the numerical analysis. The moving load subroutine DLOAD in ABAQUS was used to simulate the movement wheel loads of train on the tracks. Taking the axle weight of the train as 14 tons and the sprung mass $\mathrm{M}_{0}=750 \mathrm{~kg}$, the distribution of the load correspond to the position of the train wheel sets was shown in Fig. 4. Applying pressure on the wheel-rail contact area indicates the interaction force between the wheel and rail, which is represented by a half sine wave pulse: 
$F(t)=P_{0} \sin ^{2}(2 \pi f t)$

where, $F(t)$ is the pressure on the contact area, $P_{0}$ is the maximum pressure on the contact area, and $f$ is the loading frequency.

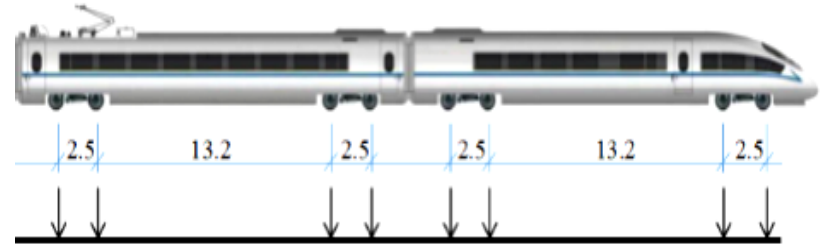

Fig. 4. Distribution of wheel sets of the train.

The loading was calculated according to the maximum axle weight of the train groups under full passengers load of 14 tons. If the maximum wheel-rail force is 1.5 times of the static wheel load, and if the contact pressure $P_{1}$ on the contact area is uniformly distributed, then $P_{1}=1050 \mathrm{MPa}$ can be obtained. In this study, the area of contact between the upper of the orbital surface element and the wheel is 0.001 $\mathrm{m}^{2}$, as shown in Fig. 5. Assuming that the resultant force on the contact area is constant, the pressure to be applied is:

$$
P_{0}=P_{1} \times \frac{A_{1}}{A_{2}}=1050 \times \frac{100}{1000}=105 \mathrm{MPa}
$$

where, $A_{1}$ is the area of contact area, $100 \mathrm{~mm}^{2}$ is taken, and $A_{2}$ is the actual loaded area.

When the subway runs at $120 \mathrm{~km} / \mathrm{h}$, the wheel and rail load operating frequencies are $12.11 \mathrm{~Hz}$ and $4.21 \mathrm{~Hz}$, respectively. The dominant acceleration frequency of the road bed caused by the moving load is below $10 \mathrm{~Hz}$ [21]. Therefore, the moving load operating frequency in this study is $5 \mathrm{~Hz}$. The half-sine pulse wave is shown in Fig. 6.

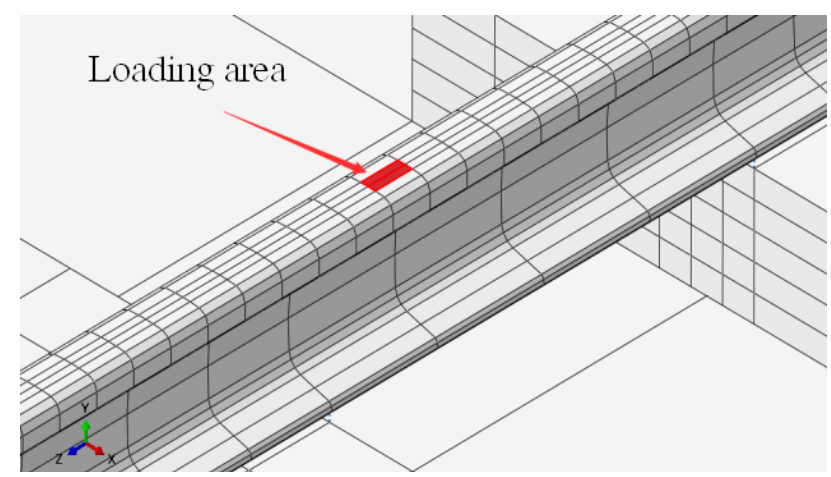

Fig. 5. Loading area on the track.

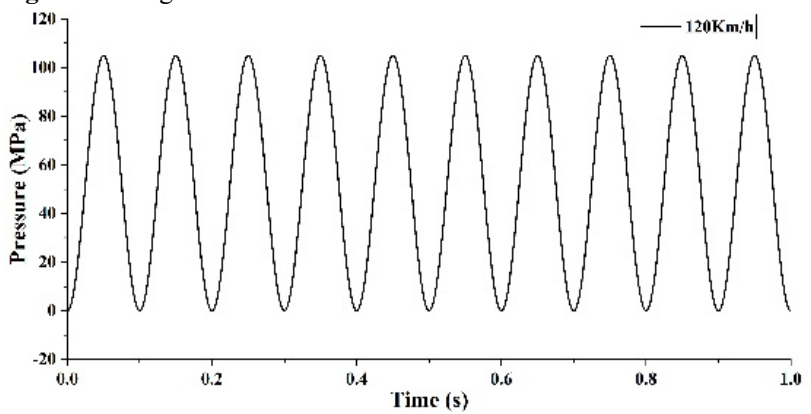

Fig. 6. Impulse pressure applied to the rails

\section{Result and discussion}

\subsection{Vertical vibration acceleration characteristics along} the longitudinal distribution

The distribution characteristics of the vertical acceleration of the track system and tunnel surrounding rock are analyzed under three situations of different train movings. First one is that train only runs the right track, Second one is that the double trains run in the same direction, and the third one is that the double trains run in the reverse direction. When the train traveling distance being half of the track length is selected as the time point, and the spatial distribution characteristics of the vibration acceleration of the track system and the surrounding rock of the ultra-small-spacing tunnel was analyzed under the train moving loaing of the single-track, the double-track in the same direction, and the double-track in the reverse direction, respectively.

Under the vibration load of the train, the vertical vibration acceleration is the largest of the acceleration components. This study only focused on the analysis of the vertical vibration acceleration caused by train operation. The vertical accelerations of the surrounding rock of the tunnel when the single train and double trains driving in the same direction, and the double trains driving in the reverse direction are shown in Fig. 7.

Figs. 8 to 11 show the distribution characteristics of the vertical vibration acceleration along the longitudinal direction of the track system and the waist of middle rock pillar wall under the single train, double trains driving in the same direction, and double trains driving in the reverse direction.

It can be seen from Fig. 8, because only the right track train is running, the vibration of the right track system is more severe than that of the left track, especially the acceleration of the rail surface of the left track is almost stationary compared with the right rail. When the double trains are traveling in the same direction, the vibration load acting on the rails is in a symmetrical state, so only the vibration acceleration distribution characteristics of the right track system are listed in Fig. 9. It can be seen from Fig. 10, when the double trains are traveling in the reverse direction, the vertical vibration accelerations of the left and right track systems are basically the same, and is roughly in an antisymmetric state.

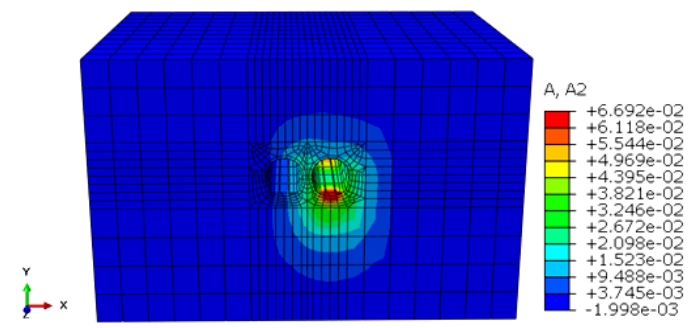

(a) Single train

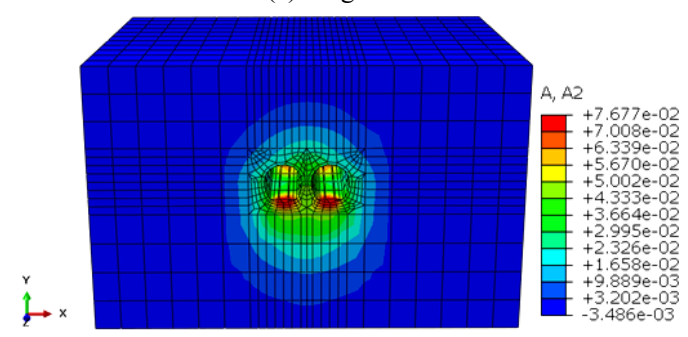

(b) Double trains in same direction 


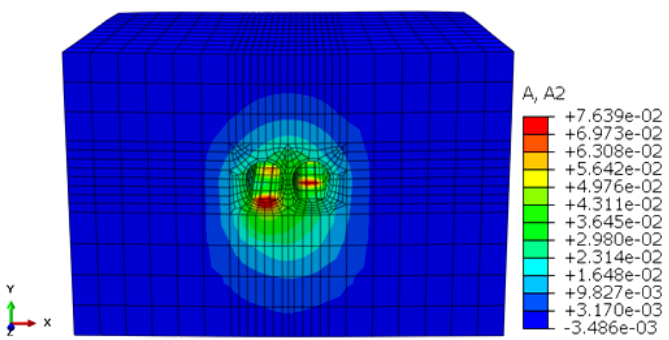

(c) Double trains in reverse direction

Fig. 7. Vertical acceleration of the surrounding rock of tunnels.

Comparison of Figs. 8 to 10, in the track system, whether it is a steel rail or a track plate and a roadbed, the vibration of the contact position of the wheel and rail of the train is more severe than the other positions. In addition, it can be seen that from the rail surface to the track plate to the roadbed, the vibration acceleration generated by the train is gradually attenuated. Due to the damping effect of the fasteners, the vibration transmitted from the rail to track slab is greatly weakened. The vertical acceleration is only $1.3 \%$ of the rail surface. The results show that the vibration acceleration of the track system is the largest when the two trains are traveling in the same direction, but the difference between the double trains in the reverse direction is very small in numerical value, and the single train is the smallest.

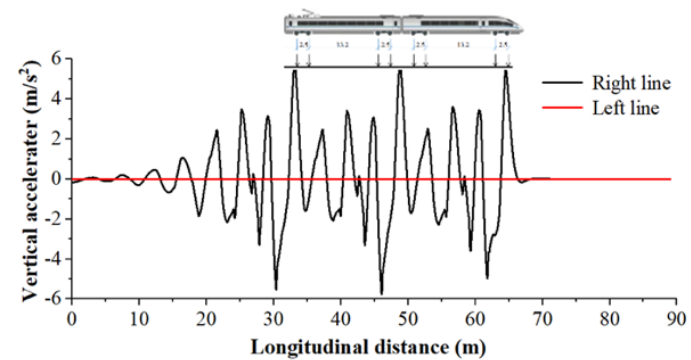

(a) Surface of the rail

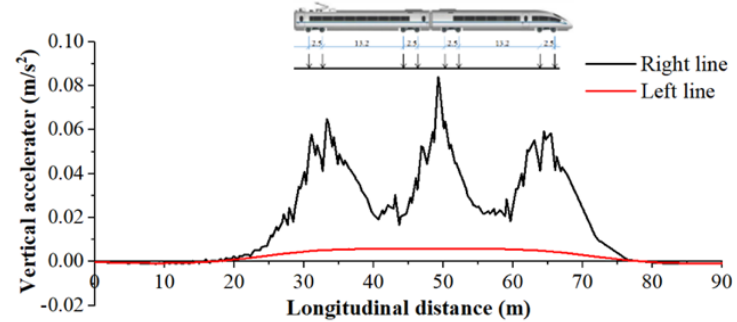

(b) Bottom of track slab

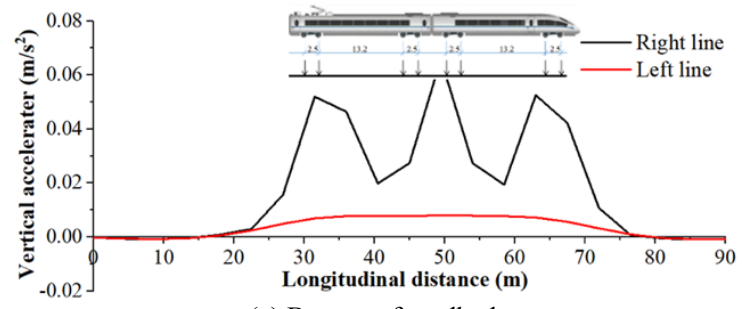

(c) Bottom of roadbed

Fig. 8. Vertical acceleration of track system with single train running.

According to the vertical acceleration at the waist of the middle rock pillar wall in the three running states of the train shown in Fig. 11, and it is about 2 times of the vertical acceleration at waist of the middle rock pillar wall when the single train is driving. In addition, the vertical vibration acceleration of the middle rock pillar is about $60 \%$ of the bottom of the roadbed when double trains are driving, and about $30 \%$ of the bottom of the roadbed when the single train is driving.

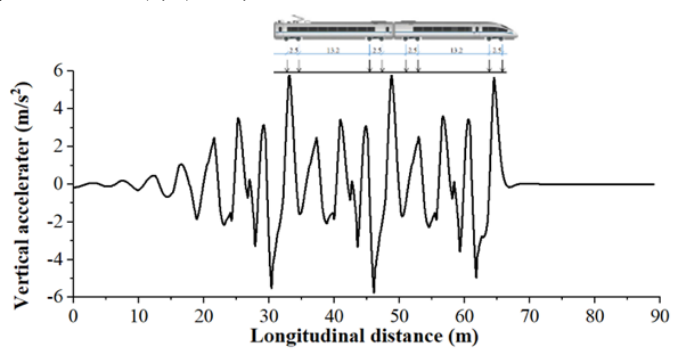

(a) Surface of the rail

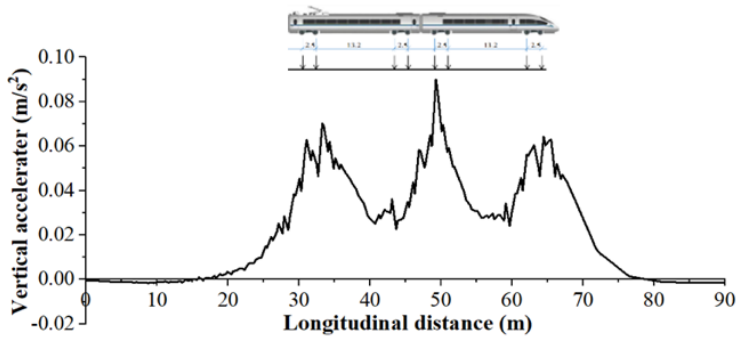

(b) Bottom of the slab

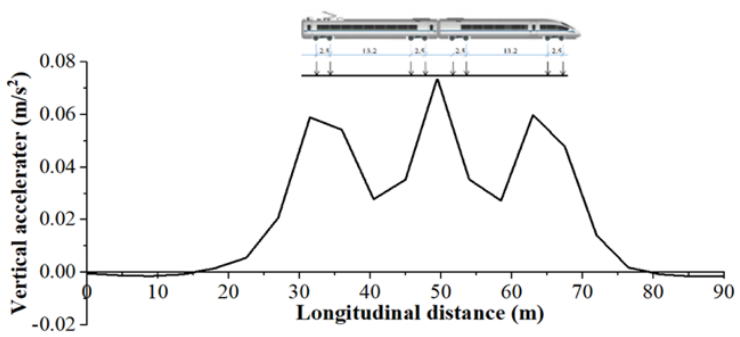

(c) Bottom of the roadbed

Fig. 9. Vertical acceleration of track system with double trains running in the same direction.

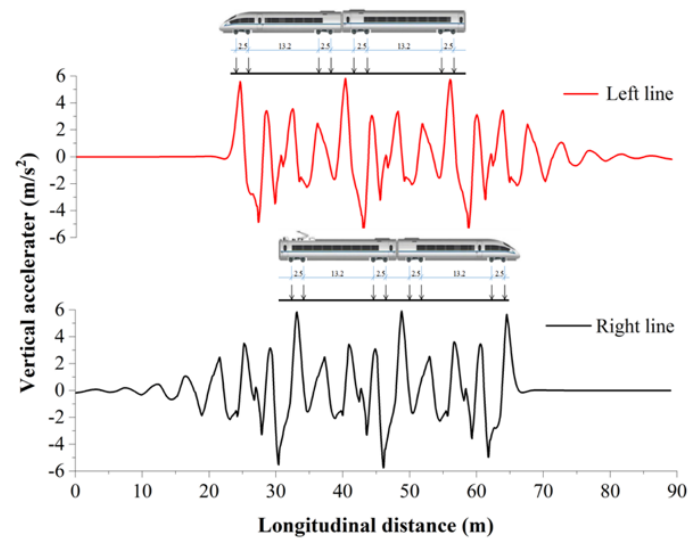

(a) Surface of the rail

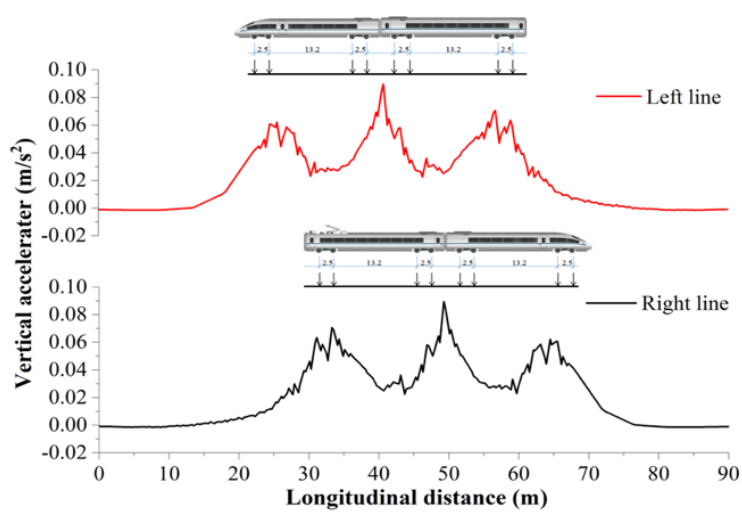

(b) Bottom of the slab 
Shuren Wang, Kunpeng Shi, Zhenhua Li, Zhichao Li and Yunfei Wang/

Journal of Engineering Science and Technology Review 12 (6) (2019) 96 - 104

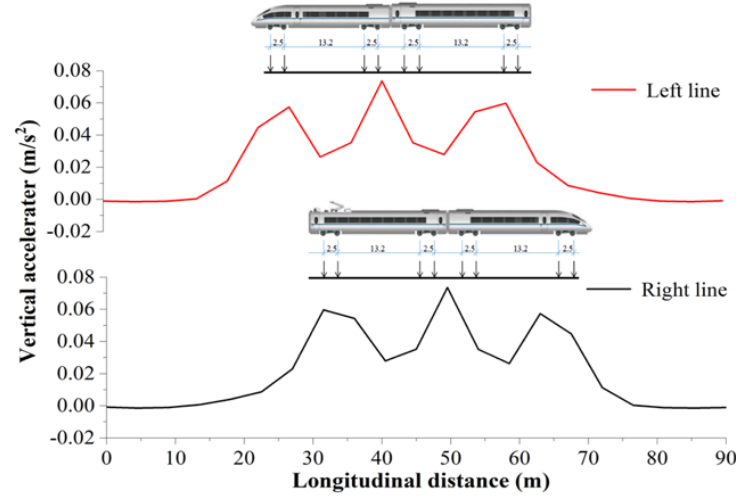

(c) Bottom of the roadbed

Fig. 10. Vertical acceleration of track system with double trains running in the reverse direction.

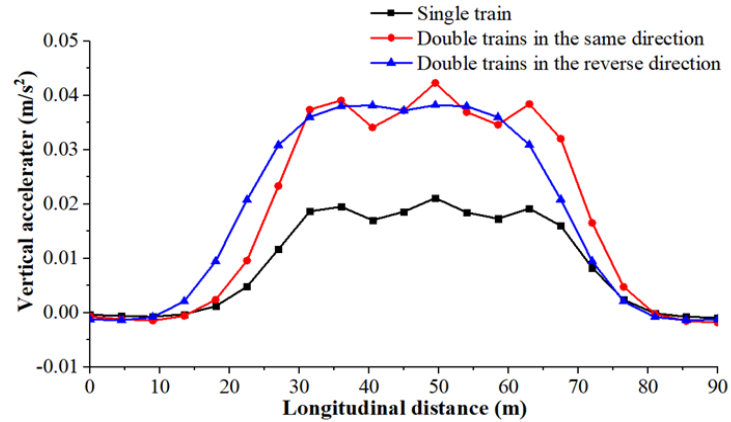

Fig. 11. Vertical acceleration of the middle rock pillar wall waist under different running condition.

\subsection{Vertical vibration acceleration characteristics along the transverse distribution}

Distribution characteristics of vertical vibration acceleration from the tunnel vault to the ground and below the track slab along the midline of model in the transverse direction, as shown in Figs. 12-14.

It can be seen from Figs. 12-14, the vertical acceleration distribution of the surrounding rock is similar along the transverse direction and roughly presents an exponential function distribution. In the depth direction, the vibration acceleration generated by train operation propagates both to the surface and underground. The vertical acceleration attenuated by about $80 \%$ at $6 \mathrm{~m}$, and the attenuated by more than $95 \%$ at $10 \mathrm{~m}$. In addition, due to the finiteness of wave velocity, there is a certain lag in the time to different depths, and the acceleration is a vector, and the particles at different depths may vibrate upward or downward at the same time, so that the recorded acceleration is positive or negative.

It can be seen from Fig. 12, when there is only right train running, the vertical acceleration on the left side of the midline is significantly smaller than that on the right side.

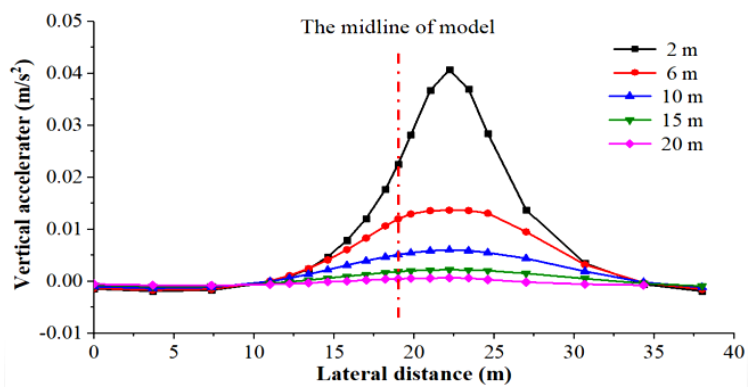

(a) Depth below middle pillar

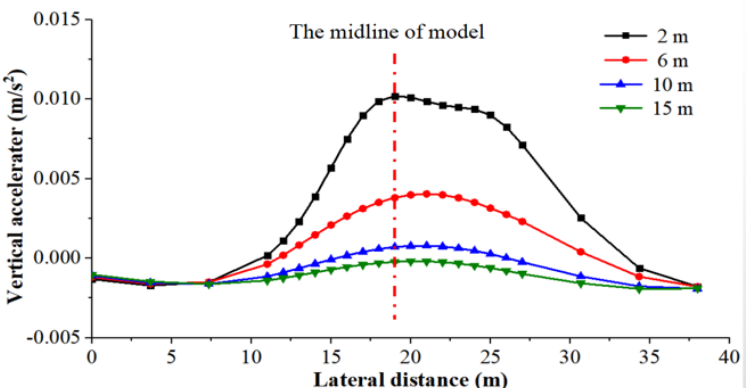

(b) Depth above vault

Fig .12. Horizontal distribution of vertical acceleration of surrounding rock with single train running.

As can be seen from Fig. 13, when the double trains are running in the same direction, the vertical acceleration along the transverse direction is symmetrical with respect to the midline. It can be seen from Fig. 13(a) that the existence of the middle rock pillar and the superposition effect of waves make the vertical acceleration curve near the lower part of the middle rock pillar tends to sag downward.

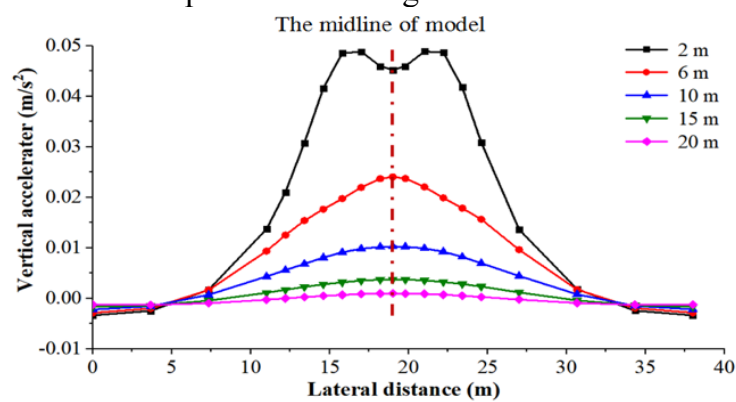

(a) Depth below middle pillar

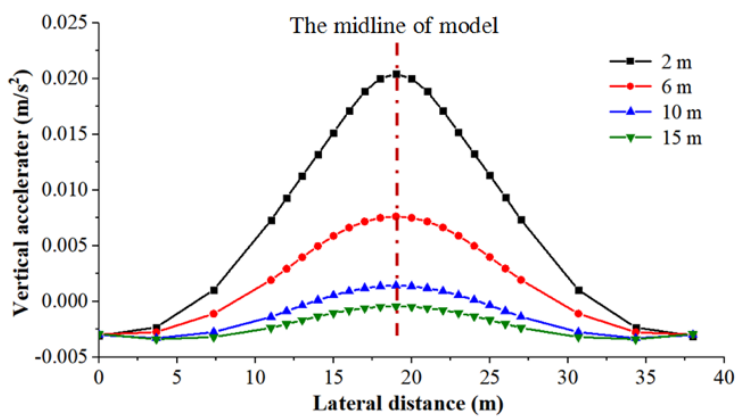

(b) Depth above vault

Fig .13. Horizontal distribution of vertical acceleration of surrounding rock with double trains running in the same direction.

From Fig. 14(a), it can be seen that the peak value of vertical acceleration curve at $2 \mathrm{~m}$ below the middle rock pillar is shifted to the left, this is due to the fact that the wheels of the left line train are located in the middle section when the train is halfway along the track. When the vibration wave travels a distance in the soil, the vertical acceleration curve keeps symmetrical distribution along the midline.

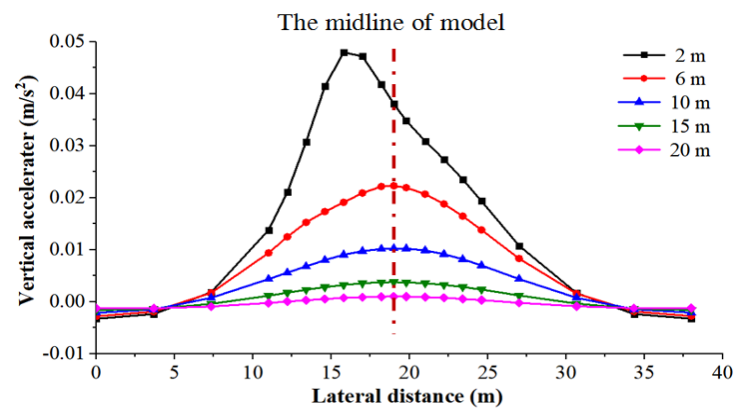

(a) Depth below middle pillar 


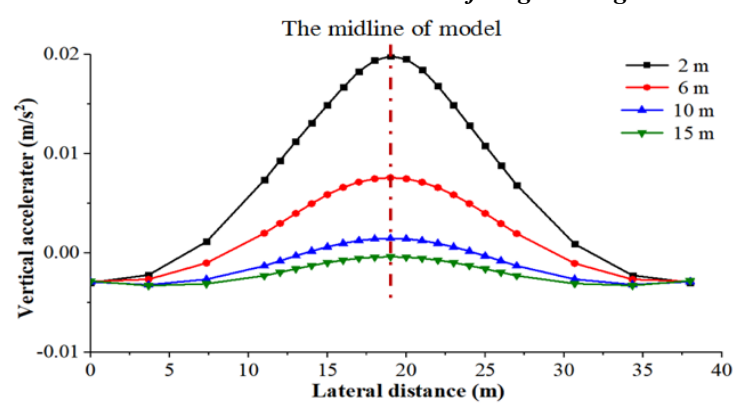

(b) Depth above vault

Fig .14. Horizontal distribution of vertical acceleration of surrounding rock with double trains running in the reverse direction.

\subsection{Vertical vibration acceleration characteristics along the vertical distribution}

Figs. 15-18 show the attenuation law of vertical vibration acceleration along the depth of the tunnel surrounding rock. Fig. 15 is the propagation law and fitting curve of vertical vibration acceleration in the depth direction below the top of the middle rock pillar of the ultra-small-spacing tunnel. As can be seen from Fig. 15, the peak value of the vertical acceleration is located at the waist of the middle rock pillar wall. and then gradually attenuate to the ends, it indirectly illustrates that the waist of the middle rock pillar wall of the tunnels is the weakest position. However, as the depth increases, the attenuation rate tends to be gentle, and the vertical acceleration attenuation is about $80 \%$ at a depth position about $8 \mathrm{~m}$ away from the waist of the middle rock pillar wall, and it tends to be 0 at a depth of $15 \mathrm{~m}$. The attenuation law fitting curve can be expressed as:

For single train:

$$
A_{2}(z)=e^{-4.5+0.2 z-0.013 z^{2}}
$$

For double trains in the same direction:

$$
A_{2}(z)=e^{-3.8+0.2 z-0.01 z^{2}}
$$

For double trains in the reverse direction:

$$
A_{2}(z)=e^{-3.8+0.17 z-0.01 z^{2}}
$$

In Eqs. (3), (4) and (5), $z$ represents the distance from the top of the middle rock pillar, and $A_{2}(z)$ represents the vertical acceleration at the depth $z$. And the fitting degree of the three curves is above $99 \%$.

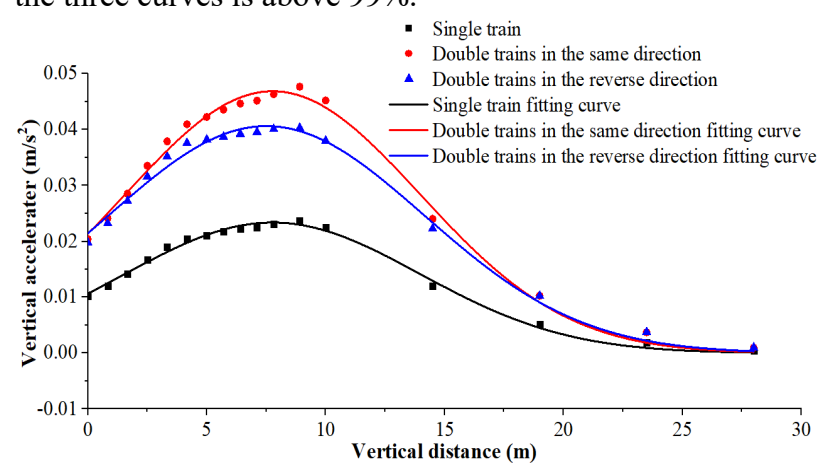

Fig. 15. Distribution of vertical acceleration with the depth of the middle rock pillar at different running conditions.

From Figs. 16 to 18 , it can be seen that the propagation laws of vertical acceleration in the depth direction below the track slab when only the right train driving, double trains driving in the same direction and double trains driving in the opposite direction all meet the exponential distribution characteristics. In addition, the attenuation of vertical acceleration at the wheel-rail contact position is generally consistent. As the depth increases, the vibration of the wave sharply weakens. At the depth of $6 \mathrm{~m}$, the attenuation rate tends to be gentle until it stops.

It can be seen from Fig. 16, the vibration under the right track slab is more severe when only the right train is running, while the vibration under the left track slab is only slight. The fitting curve expression of attenuation law is as follows:

Left line:

$$
A_{2}(z)=e^{-4.84+0.02 z-0.01 z^{2}}
$$

Right line:

$$
A_{2}(z)=e^{-2.7+0.3 z-0.04 z^{2}}
$$

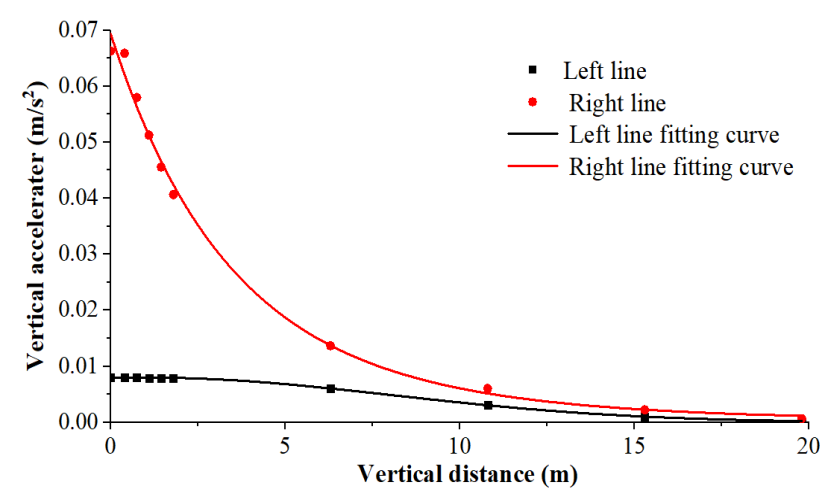

Fig. 16. Distribution of vertical acceleration with the depth of the slab at single train running.

Fig. 17 shows that the two lines travel in the same direction, and the vibrations on the lower part of the left and right line track slabs are consistent, Therefore, only the acceleration attenuation laws of the lower part of the right track slab are listed, and the fitting curve expression of the attenuation law is as follows:

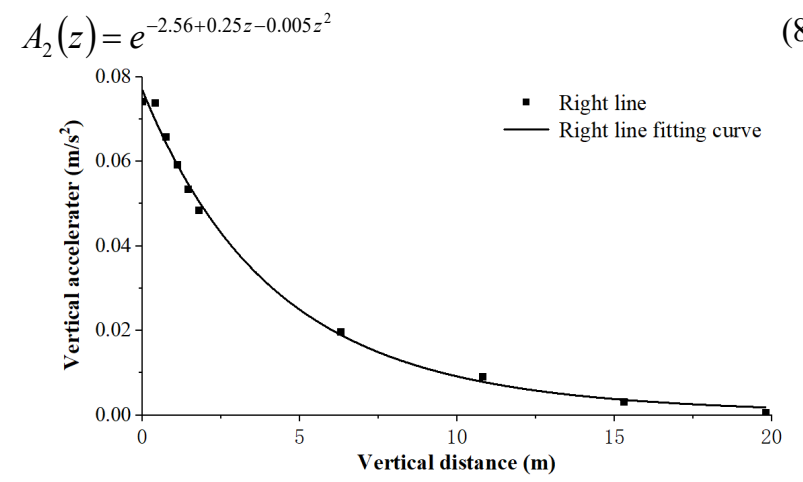

Fig. 17. Distribution of vertical acceleration with the depth of the slab at double trains running in the same direction.

It can be seen from Fig. 18, when the double trains are traveling in the opposite direction, the left line vibrates more severely than the right line at this time node due to the spatial misalignment of the two trains.

Left line: 


$$
A_{2}(z)=e^{-2.7+0.3 z-0.04 z^{2}}
$$

Right line:

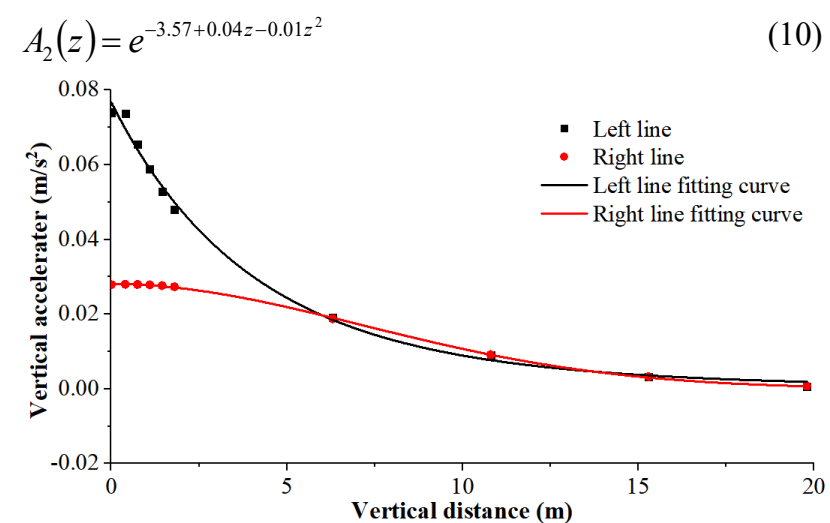

Fig. 18. Distribution of vertical acceleration with the depth of the slab at double trains running in the reverse direction.

\section{Conclusions}

Based on the Guangzhou Metro Line 3 ultra-small-spacing tunnel, a nonlinear coupled numerical model with a design speed of $120 \mathrm{~km} / \mathrm{h}$ train-track system was established. The spatial distribution characteristics of vibration acceleration of metro track system and surrounding rock during single train driving, double trains driving in the same direction and double trains driving in the opposite direction were analyzed, the main conclusions are as follows:

(1) The influence of the vibration acceleration of the double-train traveling in the same direction, in the opposite direction on the track system, and the surrounding rock of the tunnel is very close, but they are greater than those caused by a single train.

(2) During the train running, the peak value of vertical acceleration in the longitudinal direction is at the wheel rail contact areas, which is significantly higher than other positions.

(3) During the running of the train, the attenuation law of the vertical vibration acceleration in the lateral direction can be expressed by an exponential function, propagating along the midline to a range of $10 \mathrm{~m}$ on both sides, and the vertical acceleration attenuation at $6 \mathrm{~m}$ is about $80 \%$, at $10 \mathrm{~m}$ up to $95 \%$. In addition, the vertical acceleration in the range of 15 $\mathrm{m}$ below the track slap and $10 \mathrm{~m}$ above the vault can be regarded as uniform distribution.

(4) During the running of the train, the vertical vibration acceleration attenuation as an exponential function along the depth direction. In the vertical direction of the middle rock pillar, the vertical acceleration at the waist of the wall is the largest, and it attenuates sharply toward the ends of the rock pillar.

\section{Acknowledgements}

This work was financially supported by the National Natural Science Foundation of China (51774112; U1810203), the International Cooperation Project of Henan Science and Technology Department (182102410060), the Doctoral Fund of Henan Polytechnic University (B2015-67).

This is an Open Access article distributed under the terms of the Creative Commons Attribution License

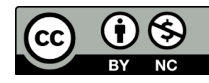

\section{References}

1. Zhang, Z. Q., Sun, J., Luo, J. Z., Deng, G. H., "Review of the influence of train-induced vibratory load on metro tunnel in loess area". Journal of Underground Space and Engineering, 12( $\left.\mathrm{S}_{1}\right), 2016$, pp. 66-74.

2. Milne, D. R. M., Le Pen, L. M., Thompson, D. J., Powrie, W. "Properties of train load frequencies and their applications". Journal of sound and vibration, 397, 2017, pp. 123-140.

3. Li, L., Zhang, M. X., Wu, H. M., "Influence of Metro Train Loading Calculation Methods on Dynamic Responses of Shield Tunnel". Journal of Shanghai Jiao Tong University, 49(07), 2015, pp. 10301034.

4. Bian, X. C., Jiang, H. G., Chang, C., "Track and ground vibrations generated by high-speed train running on ballastless railway with excitation of vertical track irregularities". Soil Dynamics and Earthquake Engineering, 76, 2015, pp. 29-43.

5. Xue, F. C., "Dynamic Responses of Subway Tunnel in Clay Stratum to Moving Loads". Arabian Journal for Science and Engineering, 42, 2017, pp. 1327-134.

6. Chen, J., Zhou, Y., "Dynamic responses of subgrade under doubleline high-speed railway". Soil Dynamics and Earthquake Engineering, 110, 2018, pp. 1-12.

7. Wu, H. N., Shen, S. L., Chai, J. C., Zhang, D, M., "Evaluation of train-load-induced settlement in metro tunnels". Proceedings of the institution of civil engineers-geotechnical endineering, 168, 2015, pp. 396-406.

8. Zhou, J. P., Chen, Y. K., Kuang, Y. Q., "Dynamic Response and Long-term Accumulation Deformation of Saturated Soft Clay under Repeated Load of Subway Trains". Science Technology and Engineering, 18(22), 2018, pp. 137-143.

9. Yuan, Z, H., Cai, Y. Q., Yuan, W., "Dynamic Response of Circular Railway Tunnel and Track System in Saturated Soil under Moving Train Loading". Rock and Soil Mechanics, 38(4), 2017, pp. 10031014.
10. Zhou, S. H., He, C., Guo, P. J., Yu, F., "Dynamic response of a segmented tunnel in saturated soil using a 2.5-D FEBE methodology". Soil Dynamics and Earthquake Engineering, 120, 2019, pp. 386-397.

11. Yang, W. B., Li, L. G., Shang, Y. C., "An experimental study of the dynamic response of shield tunnels under long term train loads". Tunnelling and Underground Space Technology, 79, 2018, pp. 67-75.

12. Yan, Q, X., Song, L, Y., Chen, H., "Dynamic Response of Segment Lining of Overlapped Shield Tunnels Under Train-Induced Vibration Loads". Arabian journal for science and engineering, 43(10), 2018, pp. 5439-5455.

13. Yan, Q. X., Li, B. J., Deng, Z. X., "Dynamic responses of shield tunnel structures with and without secondary lining up on impact by a derailed train”. Structural Engineering and Mechanics, 65(6), 2018, pp. 740-750.

14. Yi, H. Y., Qi, T. Y., Qian, W. P., "Influence of long-term dynamic load induced by high-speed trains on the accumulative deformation of shallow buried tunnel linings". Tunnelling and Underground Space Technology, 84, 2019, pp. 166-176.

15. Seong, Mha. Ho., Cho, Kwang-Il., "Dynamic Behaviors of a Curved Steel Tunnel Lining with Various Curvatures under Wind Loads due to Consecutive Passing Vehicles". Journal of The Korean Society of Hazard Mitigation, 13(4), 2013, pp. 83-90

16. Wang, S. R., Shi, K. P., Chen, W. X., Liu, S. P., "Stability analysis of middle rock pillar and cross-section optimization for ultra-small spacing tunnels". Journal of Engineering Science and Technology Review, 11(3), 2018, pp. 147-153.

17. Wang, S. R., Shi, K. P., He, Y. S., Wang, X. Q., "Dynamic response analysis of middle pillar for ultra-small spacing tunnels under train vibration loads". Journal of Engineering Science and Technology Review, 12(3), 2019, pp. 30-37.

18. Xue, F. C., "Ture Three Dimensional Dynamic Analysis of Subway Tunnel Structure and Surrounding Soil under Moving Loads". Journal of the China Railway Society, 39(6), 2017, pp. 133-140. 
Shuren Wang, Kunpeng Shi, Zhenhua Li, Zhichao Li and Yunfei Wang/

Journal of Engineering Science and Technology Review 12 (6) (2019) 96 - 104

19. Li, Y. D., Bo, J. S., Sun, Q. Q., "Implementation and Application of Viscous Voundary Conditions in ABAQUS". Journal of Disaster Prevention and Mitigation Engineering, 37(2), 2017, pp. 250-257.

20. Qi, Y. L., "Study of ABAQUS dynamic infinite element artificial

21. Auersch, L., "The excitation of ground vibration by rail traffic: Theory of vehicle-track-soil interaction and measurements on highspeed lines". Journal of Sound and Vibration, 284(1), 2005, pp. 103132. boundary". Rock and Soil Mechanics, 35(10), 2014, pp. 3007-3012. 